NBER WORKING PAPER SERIES

\title{
THE OPTIMAL TAXATION OF HEIGHT: A CASE STUDY OF UTILITARIAN INCOME REDISTRIBUTION
}

\author{
N. Gregory Mankiw \\ Matthew Weinzierl \\ Working Paper 14976 \\ http://www.nber.org/papers/w14976
NATIONAL BUREAU OF ECONOMIC RESEARCH
1050 Massachusetts Avenue
Cambridge, MA 02138

May 2009

We are grateful to Ruchir Agarwal for excellent research assistance and to Alan Auerbach, Robert Barro, Raj Chetty, Emmanuel Farhi, Ed Glaeser, Louis Kaplow, Andrew Postlewaite, David Romer, Julio Rotemberg, Alex Tabarrok, Aleh Tsyvinski, Ivan Werning,and two anonymous referees for helpful comments and discussions. The views expressed herein are those of the author(s) and do not necessarily reflect the views of the National Bureau of Economic Research.

NBER working papers are circulated for discussion and comment purposes. They have not been peerreviewed or been subject to the review by the NBER Board of Directors that accompanies official NBER publications.

(C) 2009 by N. Gregory Mankiw and Matthew Weinzierl. All rights reserved. Short sections of text, not to exceed two paragraphs, may be quoted without explicit permission provided that full credit, including $\odot$ notice, is given to the source. 
The Optimal Taxation of Height: A Case Study of Utilitarian Income Redistribution

N. Gregory Mankiw and Matthew Weinzierl

NBER Working Paper No. 14976

May 2009

JEL No. H2,H12

\begin{abstract}
$\underline{\text { ABSTRACT }}$
Should the income tax include a credit for short taxpayers and a surcharge for tall ones? The standard Utilitarian framework for tax analysis answers this question in the affirmative. Moreover, a plausible parameterization using data on height and wages implies a substantial height tax: a tall person earning $\$ 50,000$ should pay $\$ 4,500$ more in tax than a short person. One interpretation is that personal attributes correlated with wages should be considered more widely for determining taxes. Alternatively, if policies such as a height tax are rejected, then the standard Utilitarian framework must fail to capture intuitive notions of distributive justice.
\end{abstract}

\author{
N. Gregory Mankiw \\ Department of Economics \\ Littauer 223 \\ Harvard University \\ Cambridge, MA 02138 \\ and NBER \\ ngmankiw@fas.harvard.edu \\ Matthew Weinzierl \\ Harvard Business School \\ Morgan Hall 262 \\ Soldiers Field \\ Boston, MA 02163 \\ mweinzierl@hbs.edu
}




\title{
The Optimal Taxation of Height: A Case Study of Utilitarian Income Redistribution*
}

\author{
N. Gregory Mankiw Matthew Weinzierl \\ Harvard University Harvard University
}

\begin{abstract}
Should the income tax include a credit for short taxpayers and a surcharge for tall ones? The standard Utilitarian framework for tax analysis answers this question in the affirmative. Moreover, a plausible parameterization using data on height and wages implies a substantial height tax: a tall person earning $\$ 50,000$ should pay $\$ 4,500$ more in tax than a short person. One interpretation is that personal attributes correlated with wages should be considered more widely for determining taxes. Alternatively, if policies such as a height tax are rejected, then the standard Utilitarian framework must fail to capture intuitive notions of distributive justice.
\end{abstract}

This paper can be interpreted in one of two ways. Some readers can take it as a small, quirky contribution aimed to clarify the literature on optimal income taxation. Others can take it as a broader effort to challenge that entire literature. In particular, our results can be seen as raising a fundamental question about the framework for optimal taxation for which William Vickrey and James Mirrlees won the Nobel Prize and which remains a centerpiece of modern public finance.

More than a century ago, Francis Y. Edgeworth (1897) pointed out that a Utilitarian social planner with full information will be completely egalitarian. More specifically, the planner will equalize the marginal utility of all members of society; if everyone has the same separable preferences, equalizing marginal utility requires equalizing after-tax incomes as well. Those endowed with greater than average productivity are fully taxed on the excess, and those endowed with lower than average productivity get subsides to bring them up to average.

William S. Vickrey (1945) and James A. Mirrlees (1971) emphasized a key practical difficulty with Edgeworth's solution: The government does not observe innate productivity. Instead, it observes income, which is a function of productivity and effort. The social planner with such imperfect information has to limit his Utilitarian desire for the egalitarian outcome, recognizing that too much redistribution will blunt incentives to supply effort. The Vickrey-Mirrlees approach to optimal nonlinear taxation is now standard. For a prominent recent example of its application, see Emmanuel Saez (2001). For extensions of the static framework to dynamic settings, see Mikhail Golosov, Narayana Kocherlakota, and Aleh Tsyvinski (2003),

${ }^{*}$ Corresponding author: Matthew Weinzierl, 262 Morgan, Harvard Business School, Boston MA 02163; mweinzierl@hbs.edu. N. Gregory Mankiw, Littauer 223, Harvard Economics Department, Cambridge MA 02138; ngmankiw@harvard.edu. We are grateful to Ruchir Agarwal for excellent research assistance and to Alan Auerbach, Robert Barro, Raj Chetty, Emmanuel Farhi, Ed Glaeser, Louis Kaplow, Andrew Postlewaite, David Romer, Julio Rotemberg, Alex Tabarrok, Aleh Tsyvinski, Ivan Werning, and two anonymous referees for helpful comments and discussions. 
Stefania Albanesi and Christopher Sleet (2006), Kocherlakota (2006), and Golosov, Tsyvinski, and Ivan Werning (2006).

Vickrey and Mirrlees assumed that income was the only piece of data the government could observe about an individual. That assumption, however, is far from true. In practice, a person's income tax liability is a function of many variables beyond income, such as mortgage interest payments, charitable contributions, health expenditures, number of children, and so on. Following George A. Akerlof (1978), these variables might be considered "tags" that identify individuals whom society deems worthy of special support. This support is usually called a "categorical transfer" in the substantial literature on optimal tagging (e.g., Mirrlees 1986, Ravi Kanbur et al. 1994, Ritva Immonen et al. 1998, Alan Viard 2001a, 2001b, Louis Kaplow 2007). In this paper, we use the Vickrey-Mirrlees framework to explore the potential role of another variable: the taxpayer's height.

The inquiry is supported by two legs - one theoretical and one empirical. The theoretical leg is that, according to the theory of optimal taxation, any exogenous variable correlated with productivity should be a useful indicator for the government to use in determining the optimal tax liability (e.g., Saez 2001, Kaplow 2007). ${ }^{1}$ The empirical leg is that a person's height is strongly correlated with his or her income. Judge and Cable (2004) report that "an individual who is 72 in. tall could be expected to earn $\$ 5,525$ [in 2002 dollars] more per year than someone who is 65 in. tall, even after controlling for gender, weight, and age." Nicola Persico, Andrew Postlewaite, and Dan Silverman (2004) find similar results and report that "among adult white men in the United States, every additional inch of height as an adult is associated with a 1.8 percent increase in wages." Anne Case and Christina Paxson (2008) write that "For both men and women...an additional inch of height [is] associated with a one to two percent increase in earnings." This fact, together with the canonical approach to optimal taxation, suggests that a person's tax liability should be a function of his height. That is, a tall person of a given income should pay more in taxes than a short person of the same income. The policy simulation presented below confirms this implication and establishes that the optimal tax on height is substantial.

Many readers will find the idea of a height tax absurd, whereas some will find it merely highly unconventional. We encourage all readers to consider why the idea of taxing height elicits such a response even though it follows ineluctably from a well-documented empirical regularity and the dominant modern approach to optimal income taxation. If the policy is viewed as absurd, defenders of this approach are bound to offer an explanation that leaves their framework intact. Otherwise, economists ought to reconsider whether this standard approach to policy design adequately captures people's intuitive notions of redistributive justice.

The remainder of the paper proceeds as follows. In Section I we review the Vickrey-Mirrlees approach to optimal income taxation and focus it on the issue at hand - optimal taxation when earnings vary by height. In Section II we examine the empirical relationship between height and earnings, and we combine theory and data to reach a first-pass judgment about what an optimal height tax would look like for white males in the United States. We also discuss whether a height tax can be Pareto-improving. In Section III we conclude by considering some of the reasons that economists might be squeamish about advocating such a tax.

\footnotetext{
${ }^{1}$ Such a correlation is sufficient but not necessary: even if the average level of productivity is not affected by the variable, effects on the distribution of productivity can influence the optimal tax schedule for each tagged subgroup.
} 


\section{The Model}

We begin by introducing a general theoretical framework, keeping in mind that our goal is to implement the framework using empirical wage distributions.

\section{A A General Framework}

We divide the population into $H$ height groups indexed by $h$, with population proportions $p_{h}$. Individuals within each group are differentiated by their exogenous wages, which in all height groups can take one of $I$ possible values. The distribution of wages in each height group is given by $\pi_{h}=\left\{\pi_{h, i}\right\}_{i=1}^{I}$, where $\sum_{i} \pi_{h, i}=1$ for all $h$, so that the proportion $\pi_{h, i}$ of each height group $h$ has wage $w_{i}$. Individual income $y_{h, i}$ is the product of the wage and labor effort $l_{h, i}$ :

$$
y_{h, i}=w_{i} l_{h, i} .
$$

An individual's wage and labor effort are both private information; only income and height are observable by the government.

Individual utility is a function of consumption $c_{h, i}$ and labor effort:

$$
U_{h, i}=u\left(c_{h, i}, l_{h, i}\right)
$$

and utility is assumed to be increasing and concave in consumption and decreasing and convex in labor effort. Consumption is equal to after-tax income, where taxes can be a function of income and height. Note that we are assuming preferences are not a function of height.

The social planner's objective is to choose consumption and income bundles to maximize a Utilitarian ${ }^{2}$ social welfare function which is uniform and linear in individual utilities. The planner is constrained in its maximization by feasibility-taxes are purely redistributive ${ }^{3}$-and by the unobservability of wages and labor effort. Following the standard approach, the unobservability of wages and effort leads to an application of the Revelation Principle, by which the planner's optimal policy will be to design the set of bundles that induce each individual to reveal his true wage and effort level when choosing his optimal bundle. This requirement can be incorporated into the formal problem with incentive compatibility constraints.

The formal statement of the planner's problem is:

$$
\max _{c, y} \sum_{h}^{H} p_{h} \sum_{i}^{I} \pi_{h, i} u\left(c_{h, i}, \frac{y_{h, i}}{w_{i}}\right),
$$

subject to the feasibility constraint that total tax revenue is non-negative:

$$
\sum_{h}^{H} p_{h} \sum_{i}^{I} \pi_{h, i}\left(y_{h, i}-c_{h, i}\right) \geq 0,
$$

\footnotetext{
${ }^{2}$ Throughout the paper, we focus our discussion on the Utilitarian social welfare function because of its prominence in the optimal tax literature. The Vickrey-Mirrlees framework allows one to consider any Pareto-efficient policy, but nearly all implementations of this framework have used Utilitarian or more egalitarian social welfare weights. See Ivan Werning (2007) for an exception. Our analysis would easily generalize to any social welfare function that is concave in individual utilities. That is, a height tax would naturally arise as optimal with a broader class of "welfarist" social welfare functions.

${ }^{3}$ We have performed simulations in which taxes also fund an exogenous level of government expenditure. The welfare gain from conditioning taxes on height increases.
} 
and individuals' incentive compatibility constraints:

$$
u\left(c_{h, i}, \frac{y_{h, i}}{w_{i}}\right) \geq u\left(c_{h, j}, \frac{y_{h, j}}{w_{i}}\right)
$$

for all $j$ for each individual of height $h$ with wage $w_{i}$, where $c_{h, j}$ and $y_{h, j}$ are the allocations the planner intends to be chosen by an individual of height $h$ with wage $w_{j}$.

As shown by Immonen et al. (1998), Viard (2001a, 2001b), and others, we can decompose the planner's problem in (1) through (3) into two separate problems: setting optimal taxes within height groups and setting optimal aggregate transfers between height groups. Denote the transfer paid by each group $h$ with $\left\{R_{h}\right\}_{h=1}^{H}$. Then, we can restate the planner's problem as:

$$
\max _{\{c, y, R\}} \sum_{h}^{H} p_{h} \sum_{i}^{I} \pi_{h, i} u\left(c_{h, i}, \frac{y_{h, i}}{w_{i}}\right),
$$

subject to $H$ height-specific feasibility constraints:

$$
\sum_{i}^{I} \pi_{h, i}\left(y_{h, i}-c_{h, i}\right) \geq R_{h}
$$

an aggregate budget constraint that the sum of transfers is non-negative:

$$
\sum_{h}^{H} R_{h} \geq 0
$$

and a full set of incentive compatibility constraints from (3). Let the multipliers on the $H$ conditions in (5) be $\left\{\lambda_{h}\right\}_{h=1}^{H}$.

One feature of using this two-part approach is that, when we take first-order conditions with respect to the transfers $R_{h}$ we obtain

$$
\lambda_{h}=\lambda_{h^{\prime}}
$$

for all height groups $h, h^{\prime}$. This condition states that the marginal social cost of increased tax revenue (i.e., income less consumption) is equated across types. Note that this equalization is possible only because height is observable to the planner.

Throughout the paper, we will also consider a "benchmark" model for comparison with this optimal model. In the benchmark model, the planner fails to use the information on height in designing taxes. Formally, this can be captured by rewriting the set of incentive constraints in (3) to be

$$
u\left(c_{h, i}, \frac{y_{h, i}}{w_{i}}\right) \geq u\left(c_{g, j}, \frac{y_{g, j}}{w_{i}}\right)
$$

for all $g$ and all $j$ for each individual of height $h$ with wage $w_{i}$. Constraints (7) require that each individual prefer his intended bundle to not merely the bundles of other individuals in his height group but to the bundles of all other individuals in the population. Given that (7) is a more restrictive condition than (3), the planner solving the optimal problem could always choose the tax policy chosen by the benchmark planner, but it may also improve on the benchmark solution. To measure the gains from taking height into account, we will use a standard technique in the literature and calculate the windfall that the benchmark 
planner would have to receive in order to be able to achieve the same aggregate welfare as the optimal planner.

The models outlined above yield results on the optimal allocations of consumption and income from the planner's perspective, and these allocations may differ from what individuals would choose in a private equilibrium. After deriving the optimal allocations, we next consider how a social planner could implement these allocations. That is, following standard practice in the optimal taxation literature, we use these results to infer the tax system that would distort individuals' private choices so as to make them coincide with the planner's choice. When we refer to "marginal taxes" or "average taxes" below, we are describing that inferred tax system.

\section{B Analytical Results for a Simple Example}

To provide some intuitive analytical results, we consider a version of the model above in which utility is additively separable between consumption and labor, exhibits constant relative risk aversion in consumption, and is isoelastic in labor:

$$
u\left(c_{h, i}, \frac{y_{h, i}}{w_{i}}\right)=\frac{\left(c_{h, i}\right)^{1-\gamma}-1}{1-\gamma}-\frac{\alpha}{\sigma}\left(\frac{y_{h, i}}{w_{i}}\right)^{\sigma} .
$$

The parameter $\gamma$ determines the concavity of utility from consumption, ${ }^{4} \alpha$ sets the relative weight of consumption and leisure in the utility function, and $\sigma$ determines the elasticity of labor supply. In particular, the compensated (constant-consumption) labor supply elasticity is $\frac{1}{\sigma-1}$.

The planner's problem, using the two-part approach from above, can be written:

$$
\max _{\{c, y, R\}} \sum_{h=1}^{H} p_{h} \sum_{i}^{I} \pi_{h, i}\left[\frac{\left(c_{h, i}\right)^{1-\gamma}-1}{1-\gamma}-\frac{\alpha}{\sigma}\left(\frac{y_{h, i}}{w_{i}}\right)^{\sigma}\right],
$$

subject to $H$ feasibility constraints

$$
\sum_{i}^{I} \pi_{h, i}\left(y_{h, i}-c_{h, i}\right) \geq R_{h}
$$

an aggregate budget constraint that the sum of transfers is zero:

$$
\sum_{h=1}^{H} R_{h}=0
$$

and incentive constraints for each individual:

$$
\frac{\left(c_{h, i}\right)^{1-\gamma}-1}{1-\gamma}-\frac{\alpha}{\sigma}\left(\frac{y_{h, i}}{w_{i}}\right)^{\sigma} \geq \frac{\left(c_{h, j}\right)^{1-\gamma}-1}{1-\gamma}-\frac{\alpha}{\sigma}\left(\frac{y_{h, j}}{w_{i}}\right)^{\sigma} .
$$

We can learn a few key characteristics of an optimal height tax from this simplified example.

First, the first-order conditions for consumption and income imply that the classic result from Mirrlees (1971) of no marginal taxation on the top earner holds for the top earners in all height groups. Specifically, the optimal allocations satisfy:

$$
\left(c_{h, I}\right)^{-\gamma}=\frac{\alpha}{w_{I}}\left(\frac{y_{h, I}}{w_{I}}\right)^{\sigma-1}
$$

for the highest wage earner $I$ in each height group $h$.

\footnotetext{
${ }^{4}$ If $\gamma=1$, this utility function is logarithmic in consumption.
} 
Condition (12) states that the optimal allocations equate the marginal utility of consumption to the marginal disutility of producing income for all highest-skilled individuals, regardless of height. Individuals' private choices would also satisfy (12), so optimal taxes do not distort the choices of the highest-skilled. As we will see below, the highest-skilled individuals of different heights will earn different incomes under optimal policy. Nonetheless, they all will face zero marginal tax rates. This extension of the classic "no marginal tax at the top" result is due to the observability of height, which prevents individuals from being able to claim allocations meant for shorter height groups. Therefore, the planner need not manipulate incentives by distorting shorter highest-skilled individuals' private decisions, as it would if it were not allowed to condition allocations on height. ${ }^{5}$

Second, the average cost of increasing social welfare is equalized across height groups:

$$
\sum_{i}^{I} \pi_{h, i}\left(c_{h, i}\right)^{\gamma}=\sum_{i}^{I} \pi_{g, i}\left(c_{g, i}\right)^{\gamma}
$$

for all height groups $g, h$. The term $\left(c_{h, i}\right)^{\gamma}$ is the cost, in units of consumption, of a marginal increase in the utility of individual $h, i$. The planner's allocations satisfy condition (13) because, if the average cost of increasing welfare were not equal across height groups, the planner could raise social welfare by transferring resources to the height group for which this cost was relatively low. Note that in the special case of logarithmic utility, where $\gamma=1$, condition (13) implies that average consumption is equalized across height groups. ${ }^{6}$

In the next section, we continue this example with numerical simulations to learn more about the optimal tax policy taking height into account.

\section{Calculations Based on the Empirical Distribution}

In this section, we use wage data from the National Longitudinal Survey of Youth and the methods described above to calculate the optimal tax schedule for the United States, taking height into account. The data are the same as that used in Persico, Postlewaite, and Silverman (2004), and we thank those authors for making their data available for our use. ${ }^{7}$

\section{A The Data}

The main empirical task is to construct wage distributions by height group. For simplicity, we focus only on adult white males. This allows us to abstract from potential interactions between height and race or gender in determining wages. Though interesting, such interactions are not the focus of this paper. We also limit the sample to men between the ages of 32 and 39 in 1996. This limits the extent to which, if height were trending over time, height might be acting as an indicator of age. The latest date for which we have height

\footnotetext{
${ }^{5}$ This result does not depend on the highest wage $w_{I}$ being the same across groups.

${ }^{6}$ Readers familiar with recent research in dynamic optimal taxation (e.g., Golosov, Kocherlakota, and Tsyvinski, 2003) may recognize that (13) is a static analogue to that literature's so-called Inverse Euler Equation, a condition originally derived by William Rogerson (1985) in his study of repeated moral hazard. Height groups play a role in our static setting similar to that played by time periods in the dynamic setting.

${ }^{7}$ The use of wage data raises a couple of conceptual questions. First, are wages the same as ability? In principle, wages are influenced by a variety of other factors, such as compensating for work conditions. Although these factors could be correlated with height, we have no reason to believe that is the case. Second, if wages are observable, why not tax them directly? One possible answer to this question is that wages are harder for a tax authority to observe than earnings because reported hours are easily manipulable.
} 
is 1985, when the individuals were between 21 and 28 years of age. After these screens, we are left with 1,738 observations. $^{8}$

Table 1 shows the distribution by height of our sample of white males in the United States. Median height is 71 inches, and there is a clear concentration of heights around the median. We split the population into three groups: "short" for less than 70 inches, "medium" for between 70 and 72 inches, and "tall" for more than 72 inches. In principle, one could divide the population into any number of distinct height groups, but a small number makes the analysis more intuitive and simpler to calculate and summarize. Moreover, to obtain reliable estimates with a finer division would require more observations.

We calculate wages ${ }^{9}$ by dividing reported 1996 wage and salary income by reported work hours for $1996 .{ }^{10}$ We consider only full-time workers, which we define (following Persico, Postlewaite, and Silverman, 2004) as those working at least 1,000 hours. We group wages into 18 wage bins, as shown in the first three columns of Table 2, and use the average wage across all workers within a wage bin as the wage for all individuals who fall within that bin's wage range.

The distribution of wages for tall people yields a higher mean wage than does the distribution for short people. This can be seen in the final three columns of Table 2, which shows the distribution of wages by height group. Figure 1 plots the data shown in Table 2. As the figure illustrates, the distributions are similar around the most common wages but are noticeably different toward the tails. Many more tall white males have wages toward the top of the distribution and many fewer have wages toward the bottom than short white males. This causes the mean wage for the tall to be $\$ 17.28$ compared to $\$ 16.74$ for the medium and $\$ 14.84$ for the short. The tall therefore have an average wage 16 percent higher than the short in our data. Given that the mean height among the tall is 74 inches compared with 67 inches among the short, this suggests that each inch of height adds just over two percent to wages (if the effect is linear)-quite close to Persico et al.'s estimate of 1.8 percent.

\section{B What Explains the Height Premium?}

We have just seen that each inch of height adds about two percent to a young man's income in the United States, on average. Two recent papers have provided quite different explanations for this fact.

Persico, Postlewaite, and Silverman (2004) attribute the height premium to the effect of adolescent height on individuals' development of characteristics later rewarded by the labor market, such as self-esteem. They write: "We can think of this characteristic as a form of human capital, a set of skills that is accumulated at earlier stages of development." By exploiting the same data used in this paper, they find that "the preponderance of the disadvantage experienced by shorter adults in the labor market can be explained by the fact that, on average, these adults were also shorter at age 16." They control for family socioeconomic characteristics and height at younger ages and find that the effect of adolescent height remains strong. Finally, using evidence on adolescents' height and participation in activities, they conclude that "social effects during adolescence, rather than contemporaneous labor market discrimination or correlation with

\footnotetext{
${ }^{8}$ It is unclear whether a broader sample would increase or decrease the gains from the height tax. For example, adding women to the sample is likely to increase the value of a height tax, as men are systematically taller than women and, as the large literature on the gender pay gap documents, earn more on average. In this case, a height tax would serve as a proxy for gender-based taxes (see Alberto Alesina, Andrea Ichino, and Loukas Karabarbounis, 2008). Our use of a limited sample focuses attention on height itself as a key variable.

${ }^{9}$ Note that since we observe hours, we can calculate wages even though the social planner cannot. An alternative approach is to use the distribution of income and the existing tax system to infer a wage distribution, as in Saez (2001).

${ }^{10}$ There is top-coding of income in the NLSY for confidentiality protection. This should have little effect on our results, as most of these workers are in our top wage bin and thus are already assigned the average wage among their wage group.
} 
productive attributes, may be at the root of the disparity in wages across heights."

In direct contrast, Case and Paxson (2008) argue that the evidence points to a "correlation with productive attributes," namely cognitive ability, as the explanation for the adult height premium. They show that height as early as three years old is correlated with measures of cognitive ability, and that once these measures are included in wage regressions the height premium substantially declines. Moreover, adolescent heights are no more predictive of their wages than adult heights, contradicting Persico et al.'s proposed explanation. Case and Paxson argue that both height and cognitive ability are affected by prenatal, in utero, and early childhood nutrition and care, and that the resulting positive correlation between the two explains the height premium among adults.

Thus, the two most recent, careful econometric studies of the adult height premium reach very different conclusions about its source. How would a resolution to this debate affect the conclusions of this paper? Is the optimal height tax dependent upon the root cause of the height premium?

Fortunately, we can be largely agnostic as to the source of the height premium when discussing optimal height taxes. What matters for optimal height taxation is the consistent statistical relationship between exogenous height and income, not the reason for that relationship. ${ }^{11}$ Of course, if taxes could be targeted at the source of the height premium, then a height tax would be redundant, no matter the source. Depending on the true explanation for the height premium, taxing the source of it may be appropriate: for example, Case and Paxson's analysis would suggest early childhood investment by the state in order to offset poor conditions for some children. To the extent that these policies reduced the height premium, the optimal height tax would be reduced as well. However, so long as a height premium exists, the case for an optimal height tax remains.

\section{Baseline Results}

To simulate the optimal tax schedule, we need to specify functional forms and parameters. We will use the same utility function that we analyzed in Section 1.2:

$$
u\left(c_{h, i}, l_{h, i}\right)=\frac{\left(c_{h, i}\right)^{1-\gamma}-1}{1-\gamma}-\frac{\alpha}{\sigma}\left(\frac{y_{h, i}}{w_{i}}\right)^{\sigma}
$$

where $\gamma$ determines the curvature of the utility from consumption, $\alpha$ is a taste parameter, and $\sigma$ makes the compensated (constant-consumption) elasticity of labor supply equal to $\frac{1}{\sigma-1}$. Our baseline values for these parameters are $\gamma=1.5, \alpha=2.55$, and $\sigma=3$. We vary $\gamma$ and $\sigma$ below to explore their effects on the optimal policy, while an appropriate value for $\alpha$ is calibrated from the data. We determined the baseline choices of $\sigma$ and $\alpha$ as follows.

Economists differ widely in their preferred value for the elasticity of labor supply. A survey by Victor R. Fuchs, Alan B. Krueger, and James M. Poterba (1998) found that the median labor economist believes the traditional compensated elasticity of labor supply is 0.18 for men and 0.43 for women. By contrast, macroeconomists working in the real business cycle literature often choose parameterizations that imply larger values: for example, Edward C. Prescott (2004) estimates a (constant-consumption) compensated elasticity of labor supply around 3. Miles Kimball and Matthew Shapiro (2008) give an extensive discussion of labor supply elasticities, and they show that the constant-consumption elasticity is generally larger than

\footnotetext{
${ }^{11}$ In principle, individuals would have an incentive to grow less in the presence of a height tax. For example, to the extent that parents would intentionally provide a less healthy environment for their children in response to a height tax, that could influence the optimal design of a height tax. We ignore this possibility below.
} 
the traditional compensated elasticity. Taking all of this into account, we use $\frac{1}{\sigma-1}=0.5$ in our baseline estimates to be conservative. In the sensitivity results shown below, we see that the size of the optimal height tax is positively related to the elasticity of labor supply.

In our sample, the mean hours worked in 1996 was 2,435.5 hours per full-time worker. This is approximately 42 percent of total feasible work hours, where we assume eight hours per day of sleeping, eating, etc., and five days of illness per year. We choose $\alpha$ so that the population-weighted average of work hours divided by feasible hours in the benchmark (no height tax) allocation is approximately 42 percent: this yields $\alpha=2.55$. The results on the optimal height tax are not sensitive to the choice of $\alpha$.

With the wage distributions from Table 2 and the specification of the model just described, we can solve the planner's problem to obtain the optimal tax policy. For comparison, we also calculate optimal taxes under the benchmark model in which the planner ignores height when setting taxes. Figure 2 plots the average tax rate schedules for short, medium, and tall individuals in the optimal model as well as the average tax rate schedule in the benchmark model (the two lowest wage groups are not shown because their average tax rates are large and negative, making the rest of the graph hard to see). Figure 3 plots the marginal tax rate schedules. We calculate marginal rates as the implicit wedge that the optimal allocation inserts into the individual's private equilibrium consumption-leisure tradeoff. Using our assumed functional forms, the first order conditions for consumption and leisure imply that the marginal tax rate can be calculated as:

$$
T^{\prime}\left(y_{h, i}, h\right)=1+\frac{u_{y}\left(c_{h, i}, \frac{y_{h, i}}{w_{i}}\right)}{w_{i} u_{c}\left(c_{h, i}, \frac{y_{h, i}}{w_{i}}\right)}=1-\frac{\alpha\left(\frac{y_{h, i}}{w_{i}}\right)^{\sigma-1}}{w_{i}\left(c_{h, i}\right)^{-\gamma}}
$$

where $T^{\prime}\left(y_{h, i}, h\right)$ is the height-specific marginal tax rate at the income level $y_{h, i}$. Table 3 lists the corresponding income, consumption, labor, and utility levels as well as tax payments, average tax rates, and marginal tax rates at each wage level for the height groups in the optimal model. Table 4 shows these same variables for the benchmark model (with no height tax).

The graphical tax schedules provide several useful insights about the optimal solution. First, notice the relative positions of the average tax schedules in Figure 2. The average tax rate for tall individuals is always above that for short individuals, and usually above that for the medium group, with the gap due to the lump-sum transfers between groups. The benchmark model's average tax schedule lies in between the optimal tall and short schedules and near the optimal medium schedule. Other than their levels, however, the tax schedules are quite similar and fit with the conclusions of previous simulations (see Saez, 2001 and Matti Tuomala, 1990) that optimal average tax rates rise quickly at low income levels and then level off as income gets large. Finally, in Figure 3, we can see an approximately flat marginal tax rate for most incomes and then a sharp drop to zero marginal rates for the highest wage earners in each group. The drop at the top of the income distribution reflects the extension of the classic zero top marginal rate result to a model with observable height.

Turning to the data in Tables 3,4 and 5, we can learn more detail about the optimal policy. Table 3 shows that the average tax on the tall is about 7.1 percent of the average tall income, while the average tax on the medium is about 3.8 percent of average medium income. These taxes pay for an average transfer to the short of more than 13 percent of average short income. In a sense, this policy looks like a disability insurance system under which the "disabled" shorter population receives a subsidy from the "abled" taller population. But it is not the case that all "abled" workers face the same tax system. Those taller than average pay notably higher tax rates than those of average height. 
Table 4 shows that the planner also transfers resources to the short population in the benchmark Mirrlees model. Importantly, this is not an explicit transfer. Rather, it reflects the differences in the distributions of the height groups across wages. Due to the progressive taxes of the benchmark model, the tall and medium end up paying more tax on average than the short even when taxes are not conditioned on height. The resulting implicit transfers are in the same direction as the average transfers in Table 3, though substantially smaller.

Table 3 also shows that the optimal tax policy usually gives lower utility to taller individuals of a given wage than to shorter individuals of the same wage. This translates into lower expected utility for the tall population as a whole than for shorter populations, as shown at the bottom of Table 3. As Mirrlees (1971) noted, these results are typical for optimal tax models when ability is observable. Intuitively, the planner wants to equalize the marginal utility of consumption and the marginal disutility of producing income across all individuals, not their levels of utility. To see why this results in lower expected utility for the tall, suppose that wages were perfectly correlated with height, so that the planner had complete information. Then, the planner would equalize consumption across height groups, but it would not equalize labor effort across height groups. Starting from equal levels of labor effort, the marginal disutility of producing income will be lower for taller populations because they are higher-skilled. Thus, the planner will require more labor effort from taller individuals, lowering their utility. Another way to think of this is that a lump-sum tax on taller individuals doesn't affect their optimal consumption-labor tradeoff but lowers their consumption for a given level of labor effort. Thus, they work more to satisfy their optimal tradeoff and obtain a lower level of utility.

We make the optimal tax policy more concrete by using the results from Table 3 to generate a tax schedule that resembles those used by U.S. taxpayers each year-this schedule is shown as Table 5. Whereas a typical U.S. tax schedule has the taxpayer look across the columns to find his or her family status (single, married, etc.), our optimal schedule has height groups across the columns. As the numbers show, taller individuals pay substantially more taxes than shorter individuals for most income levels. For example, a tall person with income of $\$ 50,000$ pays about $\$ 4,500$ more in taxes than a short person of the same income.

Finally, we can use the results of the benchmark model to calculate a money-metric welfare gain from the height tax by finding the windfall revenue that would allow the benchmark planner to reach the same level of social welfare as the planner that uses a height tax. Table 4 shows that the windfall required is about 0.19 percent of aggregate income in our baseline parameter case. In 2008, when the national income of the U.S. economy was about $\$ 12.5$ trillion, a height tax would yield an annual welfare gain worth about $\$ 24$ billion.

\section{Sensitivity to Parameters}

Here, we explore the effects on optimal taxes of varying our assumed parameters. In particular, we consider a range of values for risk aversion and the elasticity of labor supply. To summarize the effects of each parameter, we focus on two statistics: the average transfer to the short as a percent of average short income and the windfall required by the benchmark planner to achieve the aggregate welfare obtained by the optimal planner. Table 6 shows these two statistics when we vary the risk aversion parameter $\gamma$, and Table 7 shows them when we vary the elasticity of labor supply $\frac{1}{\sigma-1}$. In both cases, when either $\gamma$ or $\sigma$ is changed, the parameter $\alpha$ must also be adjusted so as retain an empirically plausible level of hours worked. We adjust $\alpha$ to match the empirical evidence as in the baseline analysis.

Increased risk aversion (higher $\gamma$ ) increases the average transfer to the short and the gain to aggregate 
welfare obtained by conditioning taxes on height. For example, raising $\gamma$ from 1.50 to 3.50 increases the average transfer to the short from 13.38 percent to 13.97 percent of average short income and increases the windfall equivalent to the welfare gain from 0.19 percent of aggregate income to 0.28 percent. Intuitively, more concave utility makes the Utilitarian planner more eager to redistribute income and smooth consumption across types. The transfer across height groups is a blunt redistributive tool, as it taxes some low-skilled tall to give to some high-skilled short, but it is on balance a redistributive tool because the tall have higher incomes than the short on average. Thus, as risk aversion rises, the average transfer to the short increases in size and in its power to increase aggregate welfare.

Increased elasticity of labor supply (lower $\sigma$ ) also increases the optimal height tax. For example, raising the constant-consumption elasticity of labor supply from 0.5 to 3.0 increases the average transfer to the short from 13.38 percent to 31.73 percent of average short income and increases the windfall equivalent to the welfare gain from 0.19 percent of aggregate income to 0.49 percent. Intuitively, a higher elasticity of labor supply makes redistributing within height groups more distortionary, so the planner relies on the nondistortionary transfer across height groups for more of its redistribution toward the short, low-skilled. As with increased risk aversion, increased elasticity of labor supply makes the average taxes and transfers across height groups larger and gives the height tax more power to increase welfare.

\section{E Can Height Taxes Be Pareto-Improving?}

Some readers have asked whether this paper's analysis is a critique of Pareto efficiency. The answer depends on how one chooses to apply the Pareto criterion.

One approach is to consider the set of tax policies that place the economy on the Pareto frontier-that is, the frontier on which it is impossible to increase the welfare of one person without decreasing the welfare of another. This set of policies can be derived within the Mirrless approach by changing the weights attached to the different individuals in the economy. ${ }^{12}$ (By contrast, throughout the paper, we use a Utilitarian social welfare function with equal weight on each person's utility.) Nearly every specification of these social welfare weights, except perhaps a knife-edge case, has taxes conditioned on height. Thus, most Pareto efficient allocations include height-dependent taxes.

A related, but slightly different, question is whether height-dependent taxes are a Pareto improvement starting from a position without such taxes. In principle, they can be. Consider the extreme case in which height is perfectly correlated with ability. Then, income taxes could be replaced with lump-sum height taxes specific to each individual's height. By removing marginal distortions without raising tax burdens, the lumpsum taxes make all individuals better off. ${ }^{13}$ In general, the tighter the connection between height and wages and the greater the distortionary effects of marginal income taxes, the larger is the Pareto improvement provided by a height tax.

In practice, however, such Pareto improvements are so small as to be uninteresting. We have calculated the height tax that provides a Pareto improvement to the height-independent benchmark tax system derived above. We solve an augmented planner's problem that adds to the set of equations (1) through (3) new constraints guaranteeing that no individual's utility falls below what it received in the benchmark allocation, i.e., the solution to the problem described by equations (1), (2), and (7). Given the data and our benchmark parameter assumptions described above, it turns out that only an extremely small Pareto-improving height

\footnotetext{
${ }^{12}$ Werning (2007) uses this approach to study the conditions under which taxes are Pareto efficient, including in the context of observable traits.

${ }^{13}$ Louis Kaplow suggested this example.
} 
tax is available to the planner. The planner seeking a Pareto-improving height tax levies a very small (approximately $\$ 4.15$ annual) average tax on the middle height group to fund subsidies to the short ( $\$ 2.90$ ) and tall (\$2.37) groups. Not surprisingly, in light of how small the Pareto-improving height tax is, the changes in utility from the policy are trivial in size.

Nevertheless, if a nontrivial Pareto-improving height tax were possible, and if people both understood and were convinced of that possibility, it is our sense that most people would be comfortable with such a policy. In contrast, we believe most people would be uncomfortable with the Utilitarian-optimal height tax that we derived above. The difference is that the Utilitarian-optimal height tax implies substantial costs to some and gains for others relative to a height-independent policy designed according to the same welfare weights. Therefore, this paper highlights the intuitive discomfort people feel toward height taxes that sacrifice the utility of the tall for the short, not Pareto improvements that come through unconventional means such as a tax on height.

\section{Conclusion}

The problem addressed in this paper is a classic one: the optimal redistribution of income. A Utilitarian social planner would like to transfer resources from high-ability individuals to low-ability individuals, but he is constrained by the fact that he cannot directly observe ability. In conventional analysis, the planner observes only income, which depends on ability and effort, and is deterred from the fully egalitarian outcome because taxing income discourages effort. If the planner's problem is made more realistic by allowing him to observe other variables correlated with ability, such as height, he should use those other variables in addition to income for setting optimal policy. Our calculations show that a Utilitarian social planner should levy a sizeable tax on height. A tall person making $\$ 50,000$ should pay about $\$ 4,500$ more in taxes than a short person making the same income.

Height is, of course, only one of many possible personal characteristics that are correlated with a person's opportunities to produce income. In this paper, we have avoided these other variables, such as race and gender, because they are intertwined with a long history of discrimination. In light of this history, any discussion of using these variables in tax policy would raise various political and philosophical issues that go beyond the scope of this paper. But if a height tax is deemed acceptable, tax analysts should entertain the possibility of using other such "tags" as well. As scientific knowledge advances, having the right genes could potentially become the ideal tag.

Many readers, however, will not so quickly embrace the idea of levying higher taxes on tall taxpayers. Indeed, when first hearing the proposal, most people either recoil from it or are amused by it. And that reaction is precisely what makes the policy so intriguing. A tax on height follows inexorably from a well-established empirical regularity and the standard approach to the optimal design of tax policy. If the conclusion is rejected, the assumptions must be reconsidered.

One possibility is that the canonical Utilitarian model omits some constraints from political economy that are crucial for guiding tax policy. For example, some might fear that a height tax would potentially become a "gateway" tax for the government, making taxes based on demographic chartacteristics more natural and dangerously expanding the scope for government information collection and policy personalization. Yet modern tax systems already condition on much personal information, such as number of children, marital status, and personal disabilities. A height tax is qualitatively similar, so it is hard to see why it would trigger a sudden descent down a slippery slope. 
A second possibility is that the Utilitarian model fails to incorporate any role for horizontal equity. As Alan J. Auerbach and Kevin A. Hassett (1999) note, "...there is virtual unanimity that horizontal equity the extent to which equals are treated equally - is a worthy goal of any tax system." It may, for instance, be hard to explain to a tall person that he has to pay more in taxes than a short person with the same earnings capacity because, as a tall person, he had a better chance of earning more. Yet horizontal equity has no independent role in Utilitarian theory. When ability is unobservable, as in the Vickrey-Mirrlees model, respecting horizontal equity means neglecting information about exogenous personal characteristics related to ability. This information can make redistribution more efficient, as we have seen. In other words, as Kaplow (2001) emphasizes, horizontal equity gives priority to a dimension of heterogeneity across individuals-abilityand focuses on equal treatment within the groups defined by that characteristic. He argues that it is difficult to think of a reason why that approach, rather than one which aims to maximize the well-being of individuals across all groups, is an appealing one. Why would society sacrifice potentially large gains for its average member to preserve equal treatment of individuals within an arbitrarily-defined group?

A third possibility is that the Utilitarian model needs to be supplanted with another normative framework. Libertarians, for example, emphasize individual liberty and rights as the sole determinants of whether a policy is justified (see, e.g., David M. Hasen, 2007). From their perspective, any transfer of resources by policies that infringe upon individuals' rights is deemed unjust. Daniel M. Hausman and Michael S. McPherson (1996) discuss the views of Robert Nozick, a prominent Libertarian philosopher, by writing: "According to Nozick's entitlement theory of justice, an outcome is just if it arises from just acquisition of what was unowned or by voluntary transfer of what was justly owned...Only remedying or preventing injustices justifies redistribution..." Similarly, the prominent Libertarian economist Milton Friedman (1962) writes: "I find it hard, as a liberal, to see any justification for graduated taxation solely to redistribute income. This seems a clear case of using coercion to take from some in order to give to others..." How to reconstitute the theory of optimal taxation from a strictly Libertarian perspective is, however, far from clear.

Our results, therefore, leave readers with a menu of conclusions. You must either advocate a tax on height, or you must reject, or at least significantly amend, the conventional Utilitarian approach to optimal taxation. The choice is yours, but the choice cannot be avoided.

\section{References}

[1] Akerlof, George, (1978). "The Economics of 'Tagging' as Applied to the Optimal Income Tax, Welfare Programs, and Manpower Planning," American Economic Review, 68(1), March, pp. 8-19.

[2] Albanesi, Stefania and Christopher Sleet, (2006). "Dynamic Optimal Taxation with Private Information," Review of Economic Studies 73, pp. 1-30.

[3] Alesina, Alberto, Andrea Ichino, and Loukas Karabarbounis (2008). "Gender-based Taxation and the Division of Family Chores," Working Paper, November.

[4] Auerbach, Alan J. and Kevin A. Hassett, (2002). "A New Measure Of Horizontal Equity," American Economic Review 92(4), pp. 1116-1125, September.

[5] Case, Anne and Christina Paxson (2008). "Stature and Status: Height, Ability, and Labor Market Outcomes," Journal of Political Economy, 116(3). 
[6] Edgeworth, F.Y., (1897). "The Pure Theory of Taxation," Economic Journal 7, pp. 46-70, 226-238, and 550-571 (in three parts).

[7] Friedman, Milton (1962). Capitalism and Freedom. Chicago: University of Chicago Press.

[8] Fuchs, Victor R., Alan B. Krueger, and James M. Poterba. (1998). "Economists' Views about Parameters, Values, and Policies: Survey Results in Labor and Public Economics," Journal of Economic Literature, 36(3), (September), 1387-1425.

[9] Golosov, Mikhail, Narayana Kocherlakota, and Aleh Tsyvinski (2003). "Optimal Indirect and Capital Taxation," Review of Economic Studies 70, pp. 569-587.

[10] Golosov, Mikhail, Aleh Tsyvinski, and Ivan Werning (2006). "New Dynamic Public Finance: A User's Guide," NBER Macroannual 2006.

[11] Hasen, David M. (2007). "Liberalism and Ability Taxation," Texas Law Review 85(5), April.

[12] Hausman, Daniel M. and Michael S. McPherson (1996). Economic Analysis and Moral Philosophy, New York, NY: Cambridge University Press.

[13] Immonen, Ritva, Ravi Kanbur, Michael Keen, and Matti Tuomala (1998). "Tagging and Taxing," Economica 65, pp. 179-192.

[14] Judge, Timothy A., and Daniel M. Cable, (2004). "The Effect of Physical Height on Workplace Success and Income: Preliminary Test of a Theoretical Model," Journal of Applied Psychology, vol 89, no 1, 428-441.

[15] Kanbur, Ravi, Michael Keen, and Matti Tuomala (1994). "Optimal Non-Linear Taxation for the Alleviation of Income-Poverty," European Economic Review 38, pp. 1613-1632.

[16] Kaplow, Louis, (2001). "Horizontal Equity: New Measures, Unclear Principles," in Hassett, Kevin A. and R. Glenn Hubbard (eds.), Inequality and Tax Policy. Washington, D.C.: AEI Press

[17] Kaplow, Louis, (2007). "Optimal Income Transfers," International Tax and Public Finance 14, pp. 295-325.

[18] Kimball, Miles and Shapiro, Matthew. (2008). "Labor Supply: Are the Income and Substitution Effects Both Large or Both Small?" NBER Working Paper 14208, July.

[19] Kocherlakota, Narayana (2006). "Zero Expected Wealth Taxes: A Mirrlees Approach to Dynamic Optimal Taxation," Econometrica 73(5), September.

[20] Mirrlees, J.A., (1971). "An Exploration in the Theory of Optimal Income Taxation," Review of Economic Studies 38, 175-208.

[21] Mirrlees, J.A., (1986). "The Theory of Optimal Taxation", in Handbook of Mathematical Economics, edited by K.J. Arrow and M.D. Intrilligator, vol. III, ch. 24, 1198-1249.

[22] Persico, Nicola, Andrew Postlewaite, and Dan Silverman, (2004). "The Effect of Adolescent Experience on Labor Market Outcomes: The Case of Height," Journal of Political Economy, 112(5). 
[23] Prescott, Edward C. (2004). "Why Do Americans Work So Much More Than Europeans?," FRB Minneapolis - Quarterly Review, v28(1), pp. 2-14, July.

[24] Rogerson, William, (1985). "Repeated Moral Hazard," Econometrica 53, pp. 69-76.

[25] Saez, Emmanuel, (2001). "Using Elasticities to Derive Optimal Income tax Rates," Review of Economic Studies 68, pp. 205-229.

[26] Tuomala, Matti (1990). Optimal Income Tax and Redistribution. New York: Oxford University Press.

[27] Viard, Alan, (2001a). "Optimal Categorical Transfer Payments: The Welfare Economics of Limited Lump-Sum Redistribution," Journal of Public Economic Theory 3(4), pp. 483-500.

[28] Viard, Alan, (2001b). "Some Results on the Comparative Statics of Optimal Categorical Transfer Payments," Public Finance Review 29(2), pp. 148-180, March.

[29] Vickrey, W., (1945). "Measuring Marginal Utility by Reactions to Risk," Econometrica 13, 319-333.

[30] Werning, Ivan (2007). "Pareto Efficient Income Taxation," MIT Working Paper, April. 


\begin{tabular}{|rrr|}
\hline \multicolumn{3}{|c|}{$\begin{array}{l}\text { Table 1: Height distribution of adult white male } \\
\text { full-time workers in the U.S. }\end{array}$} \\
Height in inches & $\begin{array}{c}\text { Percent of } \\
\text { population }\end{array}$ & $\begin{array}{c}\text { Cumulative } \\
\text { percent of } \\
\text { population }\end{array}$ \\
\hline & & $0.1 \%$ \\
60 & $0.1 \%$ & $0.2 \%$ \\
61 & $0.1 \%$ & $0.6 \%$ \\
63 & $0.3 \%$ & $1.1 \%$ \\
64 & $0.5 \%$ & $2.1 \%$ \\
65 & $1.0 \%$ & $4.1 \%$ \\
66 & $2.0 \%$ & $7.2 \%$ \\
67 & $3.2 \%$ & $12.1 \%$ \\
68 & $4.8 \%$ & $20.5 \%$ \\
69 & $8.5 \%$ & $30.7 \%$ \\
70 & $10.1 \%$ & $45.5 \%$ \\
71 & $14.8 \%$ & $58.4 \%$ \\
72 & $12.9 \%$ & $75.4 \%$ \\
73 & $17.0 \%$ & $85.3 \%$ \\
74 & $9.8 \%$ & $93.6 \%$ \\
75 & $8.3 \%$ & $96.5 \%$ \\
76 & $3.0 \%$ & $99.1 \%$ \\
77 & $2.6 \%$ & $99.6 \%$ \\
78 & $0.5 \%$ & $99.8 \%$ \\
79 & $0.2 \%$ & $99.9 \%$ \\
80 & $0.1 \%$ & $100.0 \%$ \\
& $0.1 \%$ & \\
Source: National Longitudinal Survey of Youth, \\
Authors' calculations & & \\
\hline
\end{tabular}




\begin{tabular}{|c|c|c|c|c|c|c|c|c|c|}
\hline \multirow[t]{2}{*}{ Bin } & \multirow[t]{2}{*}{$\begin{array}{l}\text { Min wage } \\
\text { in bin }\end{array}$} & \multirow{3}{*}{$\begin{array}{l}\begin{array}{c}\text { Max wage } \\
\text { in bin }\end{array} \\
4.50\end{array}$} & \multirow{2}{*}{$\begin{array}{c}\begin{array}{c}\text { Average } \\
\text { wage in bin }\end{array} \\
\text { Pop. Avg } \\
\end{array}$} & \multicolumn{3}{|c|}{$\begin{array}{l}\text { Number of observations } \\
\text { in each height group }\end{array}$} & \multicolumn{3}{|c|}{$\begin{array}{c}\text { Proportion of each height group in } \\
\text { each wage range }\end{array}$} \\
\hline & & & & Short & Medium & $\overline{\text { Tall }}$ & Short & Medium & Tall \\
\hline 1 & - & & 2.88 & 23 & 29 & 13 & 0.043 & 0.037 & 0.030 \\
\hline 2 & 4.50 & 6.25 & 5.51 & 40 & 33 & 22 & 0.075 & 0.042 & 0.052 \\
\hline 3 & 6.25 & 8.25 & 7.24 & 57 & 63 & 29 & 0.107 & 0.081 & 0.068 \\
\hline 4 & 8.25 & 10.00 & 9.17 & 58 & 67 & 39 & 0.109 & 0.086 & 0.091 \\
\hline 5 & 10 & 12 & 10.91 & 67 & 94 & 48 & 0.126 & 0.121 & 0.112 \\
\hline 6 & 12 & 14 & 12.98 & 60 & 102 & 53 & 0.113 & 0.131 & 0.124 \\
\hline 7 & 14 & 16 & 14.98 & 56 & 68 & 44 & 0.105 & 0.087 & 0.103 \\
\hline 8 & 16 & 18 & 16.91 & 38 & 57 & 33 & 0.071 & 0.073 & 0.077 \\
\hline 9 & 18 & 20 & 18.95 & 32 & 54 & 28 & 0.060 & 0.069 & 0.066 \\
\hline 10 & 20 & 22 & 20.91 & 24 & 46 & 25 & 0.045 & 0.059 & 0.059 \\
\hline 11 & 22 & 24 & 22.83 & 22 & 38 & 21 & 0.041 & 0.049 & 0.049 \\
\hline 12 & 24 & 27 & 25.26 & 15 & 50 & 15 & 0.028 & 0.064 & 0.035 \\
\hline 13 & 27 & 33 & 29.55 & 14 & 24 & 25 & 0.026 & 0.031 & 0.059 \\
\hline 14 & 33 & 43 & 37.18 & 9 & 19 & 12 & 0.017 & 0.024 & 0.028 \\
\hline 15 & 43 & 54 & 47.19 & 9 & 19 & 7 & 0.017 & 0.024 & 0.016 \\
\hline 16 & 54 & 60 & 54.55 & 5 & 7 & 7 & 0.009 & 0.009 & 0.016 \\
\hline 17 & 60 & 73 & 63.53 & 4 & 6 & 4 & 0.008 & 0.008 & 0.009 \\
\hline \multirow[t]{3}{*}{18} & 73 & $n / a$ & 81.52 & 0 & 2 & 2 & - & 0.003 & 0.005 \\
\hline & & & & \multicolumn{3}{|c|}{ Total observations } & \multicolumn{3}{|c|}{$\begin{array}{l}\text { Average wage by height group, } \\
\text { using average wage in bin }\end{array}$} \\
\hline & & & & & & & 14.84 & 16.74 & 17.28 \\
\hline
\end{tabular}




\begin{tabular}{|c|c|c|c|c|c|c|c|}
\hline \multicolumn{8}{|c|}{ Table 3: Optimal Allocation } \\
\hline \multicolumn{8}{|c|}{ Panel A: Income and Consumption } \\
\hline \multirow[t]{2}{*}{ Wage bin } & \multirow{2}{*}{$\frac{\text { Wage }}{\frac{P o p .}{A v g}}$} & \multicolumn{3}{|c|}{ Annual income } & \multicolumn{3}{|c|}{ Annual consumption } \\
\hline & & Short & Med & Tall & Short & Med & Tall \\
\hline 1 & 2.88 & 4,086 & 4,104 & 4,107 & 27,434 & 25,332 & 24,913 \\
\hline 2 & 5.51 & 10,588 & 10,181 & 10,629 & 29,306 & 26,784 & 26,548 \\
\hline 3 & 7.24 & 15,174 & 15,386 & 15,004 & 31,178 & 28,624 & 28,064 \\
\hline 4 & 9.17 & 20,652 & 20,924 & 21,309 & 33,528 & 30,771 & 30,459 \\
\hline 5 & 10.91 & 25,730 & 26,616 & 26,442 & 35,926 & 33,273 & 32,686 \\
\hline 6 & 12.98 & 31,852 & 33,492 & 33,415 & 38,887 & 36,541 & 35,886 \\
\hline 7 & 14.98 & 38,305 & 37,846 & 39,042 & 42,292 & 38,657 & 38,672 \\
\hline 8 & 16.91 & 42,444 & 42,890 & 43,350 & 44,512 & 41,035 & 40,778 \\
\hline 9 & 18.95 & 48,882 & 50,102 & 49,636 & 47,962 & 44,607 & 43,834 \\
\hline 10 & 20.91 & 54,136 & 56,189 & 56,068 & 50,909 & 47,896 & 47,189 \\
\hline 11 & 22.83 & 59,266 & 60,036 & 59,702 & 53,832 & 49,975 & 49,091 \\
\hline 12 & 25.26 & 60,068 & 68,522 & 59,702 & 54,223 & 54,547 & 49,091 \\
\hline 13 & 29.55 & 70,412 & 70,338 & 79,398 & 58,229 & 55,315 & 57,056 \\
\hline 14 & 37.18 & 88,591 & 93,054 & 94,415 & 64,200 & 62,789 & 62,752 \\
\hline 15 & 47.19 & 134,292 & 138,770 & 127,681 & 83,286 & 83,042 & 75,221 \\
\hline 16 & 54.55 & 154,128 & 151,130 & 157,447 & 95,184 & 90,211 & 90,875 \\
\hline 17 & 63.53 & 188,292 & 182,230 & 179,611 & 119,168 & 108,755 & 103,984 \\
\hline 18 & 81.52 & & 237,496 & 240,765 & & 144,014 & 141,369 \\
\hline \multicolumn{2}{|c|}{ Expected Values } & 36,693 & 43,032 & 44,489 & 41,603 & 41,407 & 41,319 \\
\hline
\end{tabular}




\begin{tabular}{|c|c|c|c|c|c|c|c|}
\hline \multirow[t]{2}{*}{ Wage bin } & Wage & \multicolumn{3}{|c|}{ Fraction of time working } & \multicolumn{3}{|c|}{ Utility } \\
\hline & $\frac{\text { Pop. }}{\text { Avg }}$ & Short & Med & Tall & Short & Med & Tall \\
\hline 1 & 2.88 & 0.25 & 0.25 & 0.25 & 1.07 & 1.03 & 1.03 \\
\hline 2 & 5.51 & 0.33 & 0.32 & 0.33 & 1.08 & 1.04 & 1.04 \\
\hline 3 & 7.24 & 0.36 & 0.37 & 0.36 & 1.10 & 1.06 & 1.05 \\
\hline 4 & 9.17 & 0.39 & 0.40 & 0.40 & 1.12 & 1.08 & 1.07 \\
\hline 5 & 10.91 & 0.41 & 0.42 & 0.42 & 1.14 & 1.10 & 1.10 \\
\hline 6 & 12.98 & 0.43 & 0.45 & 0.45 & 1.16 & 1.13 & 1.12 \\
\hline 7 & 14.98 & 0.44 & 0.44 & 0.45 & 1.19 & 1.16 & 1.15 \\
\hline 8 & 16.91 & 0.44 & 0.44 & 0.45 & 1.21 & 1.18 & 1.17 \\
\hline 9 & 18.95 & 0.45 & 0.46 & 0.45 & 1.23 & 1.20 & 1.20 \\
\hline 10 & 20.91 & 0.45 & 0.47 & 0.47 & 1.25 & 1.22 & 1.22 \\
\hline 11 & 22.83 & 0.45 & 0.46 & 0.45 & 1.27 & 1.24 & 1.24 \\
\hline 12 & 25.26 & 0.41 & 0.47 & 0.41 & 1.29 & 1.26 & 1.26 \\
\hline 13 & 29.55 & 0.41 & 0.41 & 0.47 & 1.31 & 1.29 & 1.28 \\
\hline 14 & 37.18 & 0.41 & 0.43 & 0.44 & 1.34 & 1.32 & 1.32 \\
\hline 15 & 47.19 & 0.49 & 0.51 & 0.47 & 1.37 & 1.36 & 1.36 \\
\hline 16 & 54.55 & 0.49 & 0.48 & 0.50 & 1.41 & 1.40 & 1.39 \\
\hline 17 & 63.53 & 0.51 & 0.50 & 0.49 & 1.44 & 1.43 & 1.43 \\
\hline 18 & 81.52 & & 0.51 & 0.51 & & 1.49 & 1.48 \\
\hline \multicolumn{2}{|c|}{ Expected Values } & 0.41 & 0.42 & 0.43 & 1.175 & 1.161 & 1.158 \\
\hline
\end{tabular}




\begin{tabular}{|c|c|c|c|c|c|c|c|}
\hline \multirow[t]{2}{*}{ Wage bin } & \multirow{2}{*}{$\frac{\text { Wage }}{\frac{P o p .}{A v g}}$} & \multicolumn{3}{|c|}{ Average Tax Rate } & \multicolumn{3}{|c|}{ Marginal Tax Rate } \\
\hline & & Short & Med & Tall & Short & Med & Tall \\
\hline & 2.88 & -5.71 & -5.17 & -5.07 & 0.44 & 0.50 & 0.51 \\
\hline & 5.51 & -1.77 & -1.63 & -1.50 & 0.41 & 0.52 & 0.49 \\
\hline & 7.24 & -1.05 & -0.86 & -0.87 & 0.41 & 0.47 & 0.51 \\
\hline & 9.17 & -0.62 & -0.47 & -0.43 & 0.40 & 0.46 & 0.45 \\
\hline & 10.91 & -0.40 & -0.25 & -0.24 & 0.39 & 0.42 & 0.44 \\
\hline & 12.98 & -0.22 & -0.09 & -0.07 & 0.37 & 0.37 & 0.39 \\
\hline & 14.98 & -0.10 & -0.02 & 0.01 & 0.33 & 0.43 & 0.39 \\
\hline & 16.91 & -0.05 & 0.04 & 0.06 & 0.38 & 0.44 & 0.44 \\
\hline & 18.95 & 0.02 & 0.11 & 0.12 & 0.35 & 0.39 & 0.42 \\
\hline 1 & 20.91 & 0.06 & 0.15 & 0.16 & 0.35 & 0.36 & 0.38 \\
\hline 1 & 22.83 & 0.09 & 0.17 & 0.18 & 0.35 & 0.40 & 0.43 \\
\hline 1 & 25.26 & 0.10 & 0.20 & 0.18 & 0.50 & 0.35 & 0.58 \\
\hline 1 & 29.55 & 0.17 & 0.21 & 0.28 & 0.53 & 0.56 & 0.41 \\
\hline 1 & 37.18 & 0.28 & 0.33 & 0.34 & 0.56 & 0.53 & 0.52 \\
\hline 1 & 47.19 & 0.38 & 0.40 & 0.41 & 0.27 & 0.23 & 0.44 \\
\hline 1 & 54.55 & 0.38 & 0.40 & 0.42 & 0.24 & 0.33 & 0.26 \\
\hline 1 & 63.53 & 0.37 & 0.40 & 0.42 & 0.00 & 0.18 & 0.26 \\
\hline 1 & 81.52 & & 0.39 & 0.41 & & 0.00 & 0.00 \\
\hline Expected & Values & -0.62 & -0.34 & -0.28 & 0.39 & 0.42 & 0.43 \\
\hline \multicolumn{8}{|c|}{ Notes to Table } \\
\hline Alpha= & 2.55 & \multirow{4}{*}{\multicolumn{3}{|c|}{$\begin{array}{l}\text { Average transfer paid(+) or } \\
\text { received(-) as percent of per capita } \\
\text { income: } \\
\text { Maximum work hours per year: }\end{array}$}} & Short & Med & Tall \\
\hline Sigma $=$ & 3 & & & & $-13.38 \%$ & $3.78 \%$ & $7.13 \%$ \\
\hline Gamma= & 1.5 & & & & & & \\
\hline & & & & & 5,760 & & \\
\hline
\end{tabular}




\begin{tabular}{|c|c|c|c|c|c|c|c|c|}
\hline \multicolumn{9}{|c|}{ Table 4: Benchmark Case } \\
\hline \multirow[b]{2}{*}{ Wage bin } & \multirow[b]{2}{*}{ Wage } & \multicolumn{7}{|c|}{ Benchmark Model } \\
\hline & & $\begin{array}{l}\text { Annual } \\
\text { income }\end{array}$ & $\begin{array}{c}\text { Annual } \\
\text { consumption }\end{array}$ & $\begin{array}{l}\text { Fraction of } \\
\text { time working }\end{array}$ & Utility & $\begin{array}{l}\text { Annual tax } \\
\text { (inc.-cons.) }\end{array}$ & $\begin{array}{l}\text { Average Tax } \\
\text { Rate }\end{array}$ & $\begin{array}{l}\text { Marginal } \\
\text { Tax Rate }\end{array}$ \\
\hline 1 & 2.88 & 4,106 & 25,799 & 0.25 & 1.04 & $-21,693$ & -5.28 & 0.49 \\
\hline 2 & 5.51 & 10,479 & 27,443 & 0.33 & 1.05 & $-16,964$ & -1.62 & 0.48 \\
\hline 3 & 7.24 & 15,251 & 29,206 & 0.37 & 1.07 & $-13,955$ & -0.91 & 0.46 \\
\hline 4 & 9.17 & 20,926 & 31,461 & 0.40 & 1.09 & $-10,535$ & -0.50 & 0.44 \\
\hline 5 & 10.91 & 26,281 & 33,850 & 0.42 & 1.11 & $-7,569$ & -0.29 & 0.42 \\
\hline 6 & 12.98 & 32,962 & 37,004 & 0.44 & 1.14 & $-4,041$ & -0.12 & 0.38 \\
\hline 7 & 14.98 & 38,327 & 39,686 & 0.44 & 1.16 & $-1,359$ & -0.04 & 0.39 \\
\hline 8 & 16.91 & 42,837 & 41,913 & 0.44 & 1.19 & 924 & 0.02 & 0.43 \\
\hline 9 & 18.95 & 49,585 & 45,305 & 0.45 & 1.21 & 4,280 & 0.09 & 0.39 \\
\hline 10 & 20.91 & 55,518 & 48,507 & 0.46 & 1.23 & 7,012 & 0.13 & 0.37 \\
\hline 11 & 22.83 & 59,718 & 50,787 & 0.45 & 1.25 & 8,931 & 0.15 & 0.40 \\
\hline 12 & 25.26 & 64,720 & 53,296 & 0.44 & 1.27 & 11,424 & 0.18 & 0.44 \\
\hline 13 & 29.55 & 73,290 & 56,895 & 0.43 & 1.30 & 16,394 & 0.22 & 0.50 \\
\hline 14 & 37.18 & 92,058 & 63,385 & 0.43 & 1.33 & 28,673 & 0.31 & 0.54 \\
\hline 15 & 47.19 & 135,042 & 81,508 & 0.50 & 1.36 & 53,535 & 0.40 & 0.29 \\
\hline 16 & 54.55 & 153,574 & 92,198 & 0.49 & 1.40 & 61,376 & 0.40 & 0.28 \\
\hline 17 & 63.53 & 182,763 & 110,400 & 0.50 & 1.44 & 72,363 & 0.40 & 0.16 \\
\hline 18 & 81.52 & 236,347 & 145,040 & 0.50 & 1.49 & 91,307 & 0.39 & 0.00 \\
\hline Expected V & alues & 41,345 & 41,345 & 0.42 & 1.164 & 0 & -0.40 & 0.42 \\
\hline \multicolumn{9}{|c|}{ Notes to Table 4: } \\
\hline \multirow{4}{*}{$\begin{array}{l}\text { Alpha= } \\
\text { Sigma= } \\
\text { Gamma= }\end{array}$} & 2.55 & \multirow{2}{*}{\multicolumn{3}{|c|}{$\begin{array}{l}\text { Average transfer paid(+) or received(-) as } \\
\text { percent of per capita income: }\end{array}$}} & Short & Medium & Tall & \\
\hline & 3 & & & & $-5.71 \%$ & $1.59 \%$ & $3.23 \%$ & \\
\hline & 1.5 & \multirow{2}{*}{\multicolumn{5}{|c|}{$\begin{array}{lc}\text { Maximum work hours per year: } & 5,760 \\
\text { Windfall for benchmark to obtain optimal, as pct of aggregate income: }\end{array}$}} & \multirow{2}{*}{$0.19 \%$} & \\
\hline & & & & & & & & \\
\hline
\end{tabular}




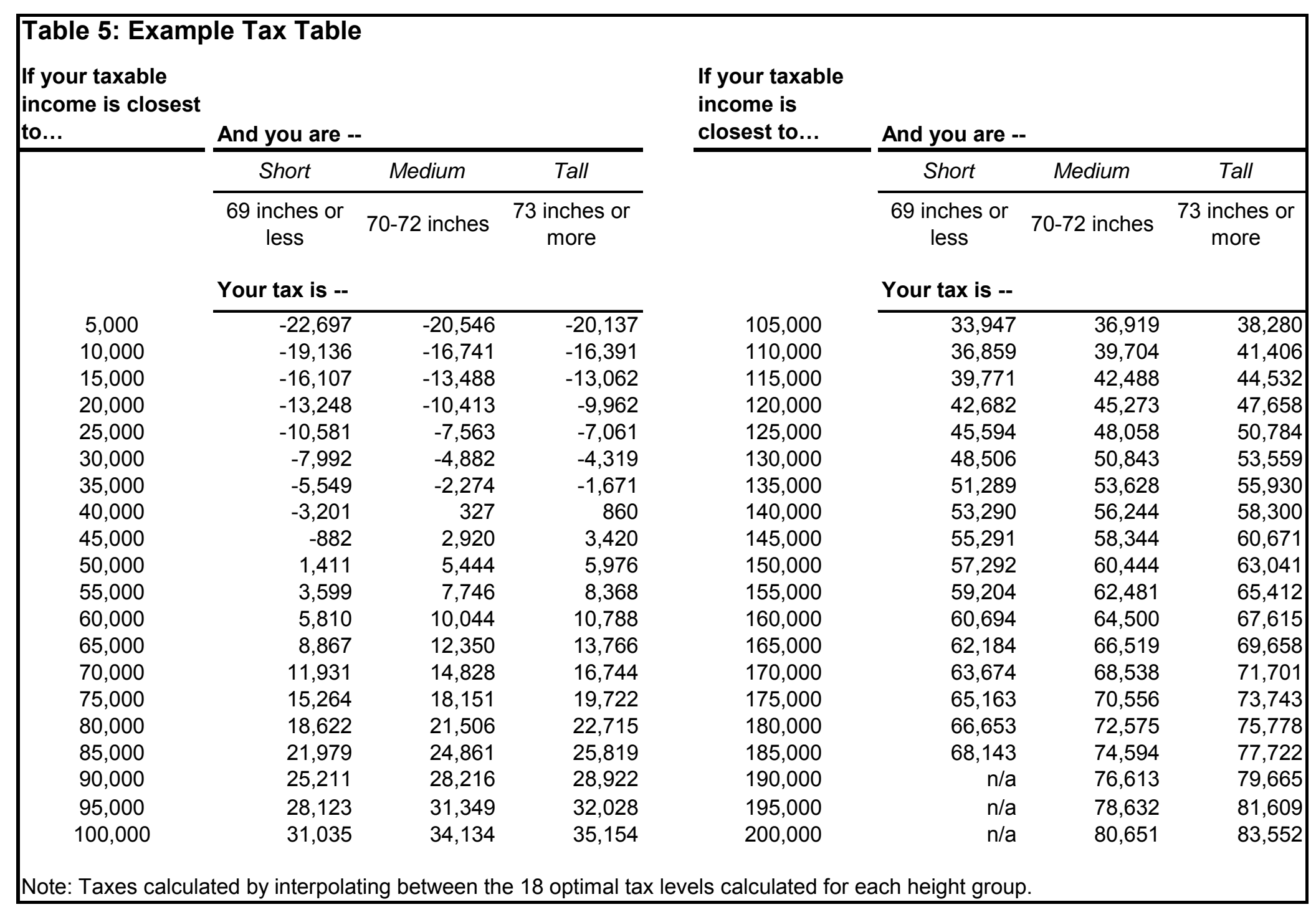




\begin{tabular}{|c|c|c|c|c|c|}
\hline \multirow[t]{3}{*}{ Table 6: Varying risk aversion } & \multirow{2}{*}{\multicolumn{5}{|c|}{ Risk aversion parameter gamma $(\mathrm{Y})$}} \\
\hline & & & & & \\
\hline & 0.75 & $\begin{array}{c}1.00: \\
u(c)=\ln (c)\end{array}$ & 1.50 & 2.50 & 3.50 \\
\hline $\begin{array}{l}\text { Average transfer to short group, as } \\
\text { percent of per capita short income: }\end{array}$ & $12.81 \%$ & $13.05 \%$ & $13.38 \%$ & $13.75 \%$ & $13.97 \%$ \\
\hline $\begin{array}{l}\text { Windfall needed for benchmark planner to } \\
\text { obtain optimal planner's social welfare, as } \\
\text { percent of aggregate income }\end{array}$ & $0.119 \%$ & $0.146 \%$ & $0.187 \%$ & $0.242 \%$ & $0.275 \%$ \\
\hline \multicolumn{6}{|c|}{ Gamma $=1.50$ is the baseline level assumed throughout paper } \\
\hline \multicolumn{6}{|c|}{ Note: Maintains $\sigma=3.00$ as in the baseline; adjusts $\alpha$ to approx. match evidence on hours worked: } \\
\hline$\alpha$ & 12.50 & 7.50 & 2.55 & 0.30 & 0.04 \\
\hline$\alpha / \sigma$ & 4.17 & 2.50 & 0.85 & 0.10 & 0.01 \\
\hline Source: National Longitudinal Survey of $\mathrm{Yol}$ & , Authors & calculations & & & \\
\hline
\end{tabular}

\begin{tabular}{|c|c|c|c|c|c|}
\hline \multirow[t]{3}{*}{ Table 7: Varying labor supply elasticity } & & & & & \\
\hline & \multicolumn{5}{|c|}{ Constant-consumption elasticity of labor supply } \\
\hline & 0.20 & 0.30 & 0.50 & 1.00 & 3.00 \\
\hline Value for parameter sigma $(\sigma)$ & 6.00 & 4.33 & 3.00 & 2.00 & 1.33 \\
\hline $\begin{array}{l}\text { Average transfer to short group, as } \\
\text { percent of per capita short income: }\end{array}$ & $11.21 \%$ & $11.93 \%$ & $13.38 \%$ & $17.06 \%$ & $31.73 \%$ \\
\hline $\begin{array}{l}\text { Windfall needed for benchmark planner to } \\
\text { obtain optimal planner's social welfare, as } \\
\text { percent of aggregate income }\end{array}$ & $0.097 \%$ & $0.134 \%$ & $0.187 \%$ & $0.274 \%$ & $0.493 \%$ \\
\hline \multicolumn{6}{|c|}{\begin{tabular}{|l|l|l} 
Sigma $=3.00$ is the baseline level assumed throughout paper & & \\
\end{tabular}} \\
\hline \multicolumn{6}{|c|}{ Note: Maintains $\gamma=1.50$ as in the baseline; adjusts $\alpha$ to approx. match evidence on hours worked: } \\
\hline a & 30.00 & 8.00 & 2.55 & 1.15 & 0.65 \\
\hline$\alpha / \sigma$ & 5.00 & 1.85 & 0.85 & 0.58 & 0.49 \\
\hline Source: National Longitudinal Survey of Yo & ר, Authors & Iculations & & & \\
\hline
\end{tabular}


Figure 1: Wage distribution of adult white males in the U.S. by height

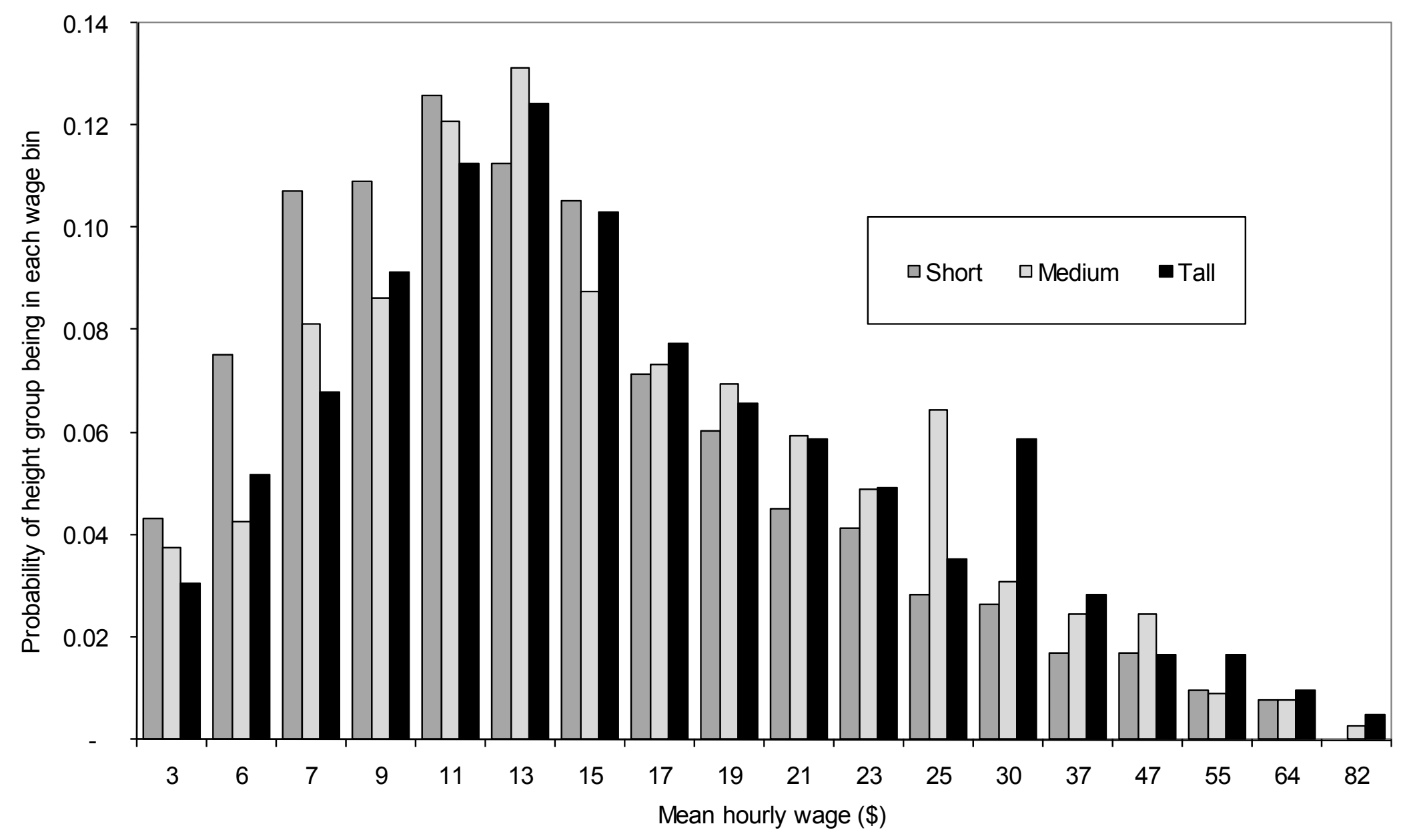

Source: National Longitudinal Survey of Youth and authors' calculations 


\section{Figure 2: Average Tax Rates}

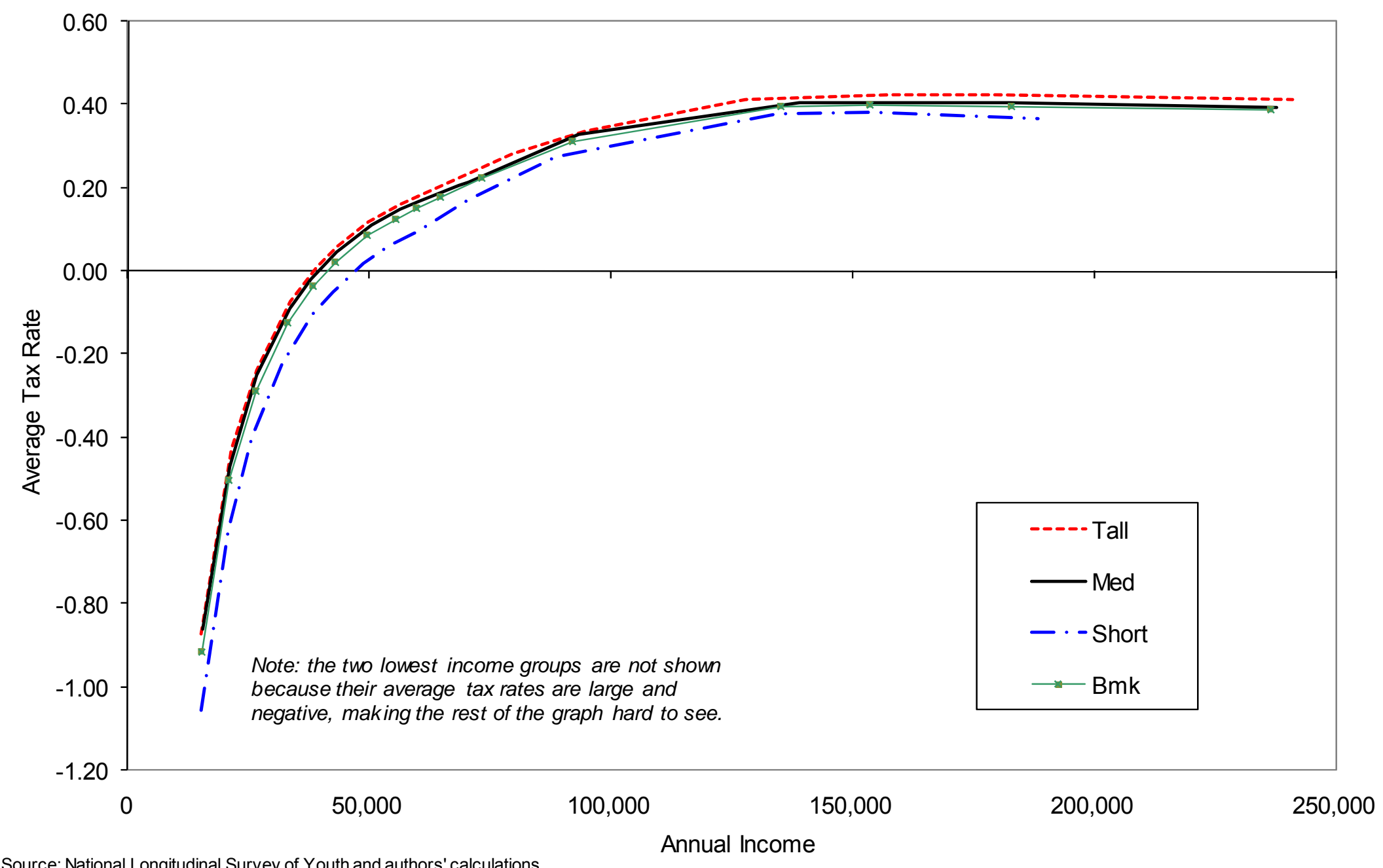


Figure 3: Marginal Tax Rates

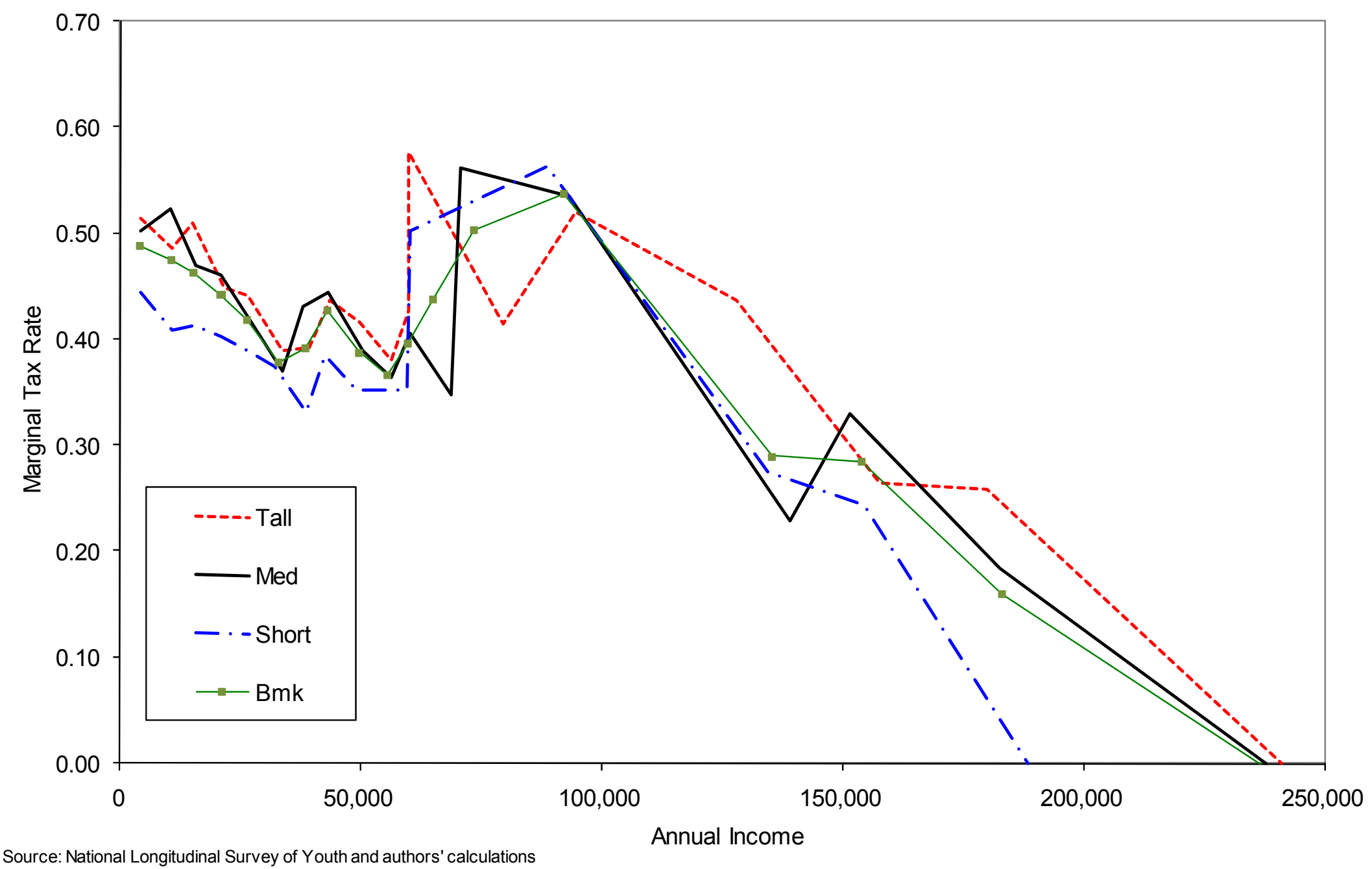

Source: National Longitudinal Survey of Youth and authors' calculations 